Teaching and Learning (2009) 5(1), 45-52

\title{
Teachers Learning Together Project: Differentiation in Math
}

\author{
VANDANA VERMA \\ Hamilton-Wentworth District School Board \\ FRAN ELLIOT \\ Hamilton-Wentworth District School Board \\ JANET IMRIE \\ Hamilton-Wentworth District School Board \\ BRIGITTE GEAR \\ Hamilton-Wentworth District School Board \\ MICHAEL BERG \\ Hamilton-Wentworth District School Board
}

\begin{abstract}
Having experienced success in increasing EQAO literacy scores through differentiated instruction initiatives for literacy, five mathematics teachers in a small, inner-city JK to Grade 3 school joined together in an action research project to investigate differentiation techniques to improve their math instruction. Together, they developed a series of lessons to teach problemsolving to Grades 1, 2, and 3 students, and selected specific differentiation strategies to incorporate across the classes. Findings revealed that students demonstrated an increased repertoire of math strategies, improved organization of student work, increased ability to justify their thinking in written and oral form, and a new enthusiasm for problem solving.
\end{abstract}

\section{Introduction}

When opportunity knocks, enthusiastic teachers respond - at least they did at our small inner city J.K. to Grade 3 school in Hamilton, Ontario. For the last two years, data results from the EQAO testing of our students indicated a strong need for targeted instruction in Math, specifically in the problem solving strand, across all grade levels of our school. Having experienced success in increasing EQAO literacy scores through the board’s Differentiated Instruction literacy initiatives, we felt that applying appropriate differentiated techniques to problem solving could possibly impact student achievement in this area as well. When the Elementary Teachers Federation of Ontario (ETFO) offered 
Teachers Learning Together Project: Differentiation in Math

support for teacher teams to work on action research projects, we were anxious to participate. Finally! A project that acknowledged that teachers have a desire to improve student learning and gain new knowledge that allows them to test out new innovative ideas!

The ETFO Teachers Learning Together Project

Teacher teams presented proposals to ETFO in hopes of gaining funding support, and we were one of approximately fifty proposals from across Ontario that were accepted. Our team consisted of five members: a Grade 2 teacher, two Grade 3 teachers, a Grade 1 teacher, and a teacher who had left her classroom position for an information technology position during the summer reorganization of the school faculty. She was now the Computer/library/music teacher with an interest in investigating how technology might be a useful tool in the differentiation process. Our action research project would allow us to investigate differentiated instruction techniques that improve student numeracy skills through problem solving.

In August, our team went to Toronto to attend a symposium sponsored by ETFO that provided an overview of action research and an opportunity to meet other teams of teachers from all over Ontario who had responded to ETFO’s learning opportunity. In that full day session, we developed our research question, "How will differentiated instruction improve the primary grade students’ learning of number sense through problem-solving?” We returned to our school motivated and empowered, and ready to conduct our year-long action research. ETFO would also be supporting our research throughout the year by providing us with five full days of release time, two amazing professors from Brock to mentor us, a binder on how to conduct action research, and access to a research assistant and online database research resources.

The goal of our action research was to improve student numeracy skills through problem solving and differentiated instruction. To do this we focused on small group instruction for addition and subtraction, similar in format to Guided Reading instruction where students were grouped by ability or a common learning need. Our literature search 
revealed that there were many books and resources on differentiated instruction in language, but there were few when it came to mathematics. Dr. Spence, the Director of Education for the Hamilton-Wentworth District School Board, kindly paid for some books that we wanted to review, and we borrowed many others from the board. We also contacted the Numeracy Secretariat and Damian Cooper, an expert on assessment, for other insights into the use of differentiated instruction in math. We reviewed the Context for Learning Mathematics (Grade 3) kits (Fosnot, 2007), Mathematics (Nelson, 2004), Math Makes Sense (2006), as well as Teaching Student-centered Math (Van de Walle \& Lovin, 2004).

Using these resources, we developed a series of lessons for each grade level that met our teaching styles and our students' learning needs, while incorporating specific small group differentiation techniques recommended by the literature to improve numeracy and problem solving. The literature review also provided techniques for PeerAssisted Learning (P.A.L.) (Access Center, n.d.) which allowed the students to work together in flexible groupings and/or partners, while the teacher provided small group instruction to groups of students of similar needs. Students with the lowest math achievement were targeted to receive small group instruction in the computer lab, using KIDPIX software and a printer.

Our action plan was to use the first 2 weeks in January as our 10 day intervention period when we would use the lessons and classroom differentiation techniques. All parents received an Information and Consent form and a "math interest" survey. A preassessment to determine students’ attitudes towards math and ability was conducted.

Prior to our two week intervention period, we used class time preparing our students to work independently using a format for solving problems and clear expectations regarding behaviour. Each teacher had the flexibility to structure the independent work time of their students to suit their own classroom dynamics. Some students worked on problems independently, while others used a peer assisted learning (P.A.L.) format. A series of differentiated problems were offered so all students could be successful.

During the small group instruction, teachers tailored the learning to levels of ability. Some groups needed additional instruction about solving word problems, while 
others were ready to learn addition and subtraction strategies. In this way the learning was differentiated for each group. The rest of the students practiced what they learned in the small group instruction session during the independent portion of the period.

After the 10 days of lessons, we re-surveyed the students with the "math interest" inventory and the post-assessment.

\section{Data Sources and Analysis}

During the implementation of the intervention, we collected several data sources, including the following:

Pre-test/Post-test. All students were given a pre-test which was a word problem. We looked at how the students solved the problem. That information provided us with a baseline of student knowledge which was used to determine what we needed to teach in our differentiated groups. The post-test was also a word problem that was analyzed for any improvement in the students’ problem-solving abilities.

Pre-test and post-test interest surveys. The interest surveys included questions such as: Do you like math? Are you good at math, why or why not? Why do you think we learn abut math? The post survey included the questions: Did you enjoy doing math with the teacher in a small-group, why or why not? Did you enjoy problem solving, why or why not? The surveys were used to determine if the intervention impacted how students felt about doing math or working in differentiated groups.

Daily student work. While the teachers were working with the small group, the other students worked on word problems with a partner or individually, depending on the class. Students' work was collected in workbooks which we analyzed daily for students' improvement and future instructional needs.

Co-operative questionnaire and problem solving self-assessment rubric. Every day after the students worked with their partners, the grade 1 students completed a cooperative questionnaire. They assessed how well they worked with their partner. The self-assessment rubric also had the students assess how successful they had been at the problem-solving for that day. 
Teachers Learning Together Project: Differentiation in Math

Anecdotal comments. Each of the team members recorded daily comments about how the students were learning and progressing. We also reviewed student work and made notes to the students on what they were doing well and what they needed to continue to work on.

\section{Findings}

As teachers we had some specific goals in mind; therefore, we analyzed the data using these specific criteria. We wanted to see:

- Increased repertoire of math strategies

- Improved organization of student work

- Justification of student thinking in written and oral form

- Enthusiasm for problem solving

When presented with math problems, our students began to use two or three different math strategies instead of just one. Their pictures were math pictures that functioned to enhance the problem solving aspect. Our students demonstrated confidence in talking about the math strategies they used.

Organization of work improved, especially in our Grade Two and Three classes. More students were following the format introduced and their work clearly showed the steps using pictures, numbers, and words.

All grades showed improvement in their ability to explain their thinking. In Grade One and Two, this was evident in the oral talk where students made logical connections but the Grade Three students were writing competently, and developing judgments that demonstrated a solid understanding.

Our post survey indicated that many students embraced the new way of learning and had a positive change in attitude towards problem solving. We had gone from students saying, "Math is not important" to "Math is important because it is all around us!" 
Teachers Learning Together Project: Differentiation in Math

\section{Impact and Implications}

The results of our research are divided into two distinct categories: Student Learning and Teachers as Professionals.

Related to Student Learning: The analysis of student responses on the pre/post tests indicated that small-group math instruction is a powerful teaching and learning format that students enjoy. By providing students with the tools, time, and explicit teaching, it directly impacted student motivation and success.

We asked the students if they enjoyed doing math in the small-groups. One student's response was "Yes, because you get to learn more and have more fun with math.” Another student referred to problem solving by saying, "It is better than playing." Students enjoyed the small-group time with the teacher, with many of them stating that they were looking forward to math class. When the project was over, one student asked, “Can we still do small math groups?” Also, students were motivated to assist one another with math problems.

Students who were in the technology math group enjoyed using the printer to print out their work. Individual students could see how much work they had completed. It was a visual means of assessing their progress. It addressed their kinesthetic needs to get out of their seats, to get the paper from the printer and put it on the floor.

However, students needed more time than two weeks to become successful at P.A.L. learning and small-group math instruction. They needed more time because a lot of training was involved. The research project was implemented in January, and consequently, many students were absent due to sickness or weather conditions. These absences often disrupted the flow of the implementation and some students never got completely adjusted to the change in routine. Due to this factor, another week or two would have been beneficial to our research.

Related to Teachers as Professionals: The analysis of anecdotal comments and minutes of group meetings indicated that there were many aspects of a comprehensive literacy approach of modeled, shared, guided, and independent lessons that would be effective in 
math instruction. We also felt that some strands of math, such as numeration, lend themselves to small-group instruction better than others. We valued small-group math instruction as a way to provide teachers with an immediate assessment and next steps for instruction. Therefore, serious thought should be given to using this teaching format for periods of time throughout the year.

The use of technology through Kid Pix, a popular students’ computer application, was a useful tool in differentiation of problem solving in numeracy. When the students printed their work out on the 8.5 " by 11 " sheets and assembled them on the carpet, it naturally made a bar graph for the amount of work done. This further motivated the students to complete their work.

In these ways we had achieved success for our students......but they were not the only ones to benefit! As teachers we felt that we had learned something too. The impact of doing a group project like this was powerful. It provided us with opportunities to build leadership and communication skills. Having to articulate what we are doing and why we were teaching this way strengthened our own professional skills, gave voice to our own professional knowledge, and in the end, solidified our belief that differentiated instruction works.

\section{Conclusion}

In the fall of 2009, we plan to continue providing small-group instruction and work as a team in the area of problem solving and number sense as well. This could expand to the other strands of math.

The ETFO project has given us an opportunity to reflect deeply on our practice and to explore different ways to assess the teaching-learning process. We have become risk takers in our teaching practice because we supported each other, and the respect and collegiality we developed from the action research project makes our team stronger. We were engaged in our math learning and so were our students. But, most significantly, that precious commodity of time that was provided in the project that allowed us to complete an action research project really made a difference. We found that when teachers have the 
time to connect with other professionals, time to meet together, and time to make the changes necessary, everyone benefits!

\section{Acknowledgement}

This report describes an action research project sponsored by the Elementary Teachers' Federation of Ontario. The teacher team involved was mentored by Dr. Candace Figg and Dr. Kamini Jaipal-Jamani from the Faculty of Education Department at Brock University.

\section{References}

Access Center. (n.d.). Using peer tutoring for Math. Retrieved October 1, 2008, from http://www.k8accesscenter.org/documents/UsingPeerTutoringforMath06-06-2.pdf

Fosnot, C. T. (2007). Context for learning Mathematics (Grade 3). Orlando, FL: Harcourt School Publishers.

Math makes sense (Grade 3). (2004). Toronto, ON: Pearson Education Canada.

Nelson Mathematics (Grade 1-3). (2004). Toronto, ON: Thomson Canada.

Van de Walle, J. A., \& Lovin, L. H. (2006). Teaching student-centered Mathematics, Grades K-3. Toronto, ON: Pearson Education.

Van de Walle, J. A., \& Lovin, L. H. (2006). Teaching student-centered Mathematics, Grades 3-5. Toronto, ON: Pearson Education. 